\title{
Primary Mediastinal Large B-cell Lymphoma Exhibiting Endobronchial Involvement
}

\author{
Midori Shimada ${ }^{1}$, Minoru Fukuda ${ }^{2}$, Kensuke Horio $^{3}$, Takayuki Suyama ${ }^{1}$, Takeshi Kitazaki ${ }^{1}$, \\ Kohji Hashiguchi ${ }^{1}$, Masaaki Fukuda ${ }^{1}$, Kazuto Shigematsu ${ }^{4}$, Yoichi Nakamura ${ }^{5}$, \\ Takuya Honda ${ }^{2}$, Kazuto Ashizawa ${ }^{2}$ and Hiroshi Mukae ${ }^{6}$
}

\begin{abstract}
Primary mediastinal large B-cell lymphoma (PMLBCL) is one of the subtypes of diffuse large B-cell lymphoma. We experienced a rare case of PMLBCL that exhibited endobronchial involvement. A 33-year-old Japanese female with the chief complaints of epigastralgia, back pain, and nausea visited a primary care hospital. Computed tomography of the chest and abdomen demonstrated a bulky mass in the left anterior mediastinum, multiple pulmonary nodules, axillary lymph node swelling, and a pancreatic tumor. Fiberoptic bronchoscopy showed a white-tinged irregularly shaped endobronchial tumor accompanied by capillary vessel dilation in the left upper lobar bronchus. Taken together, these findings resulted in a diagnosis of PMLBCL.
\end{abstract}

Key words: primary mediastinal large B-cell lymphoma, endobronchial involvement

(Intern Med 55: 3147-3150, 2016)

(DOI: 10.2169/internalmedicine.55.7117)

\begin{abstract}
Introduction
Primary mediastinal large B-cell lymphoma (PMLBCL) is one of the subtypes of diffuse large B-cell lymphoma (DLBCL), which is derived from B cells of thymic origin (1-4). It usually occurs in young women and presents as a rapidly enlarging anterior mediastinal mass. The most common symptoms of the disease including coughing, chest pain, dyspnea, and venous obstruction. Recently, endobronchial ultrasound-guided transbronchial needle aspiration (EBUS-TBNA) has been reported to be useful for investigating cases of suspected lymphoma (5); however, PMLBCL are rarely directly observable during endoscopy. We herein present the case of a young woman with PMLBCL, in which an endobronchial tumor was directly observed and diagnosed by bronchoscopy.
\end{abstract}

Case Report

A 33-year-old Japanese female with the chief complaints of epigastralgia, back pain, and nausea visited a primary care hospital. In addition to her chief complaints, the patient had also been suffering from a cough, general malaise, and loss of appetite for a month. Computed tomography (CT) of the chest and abdomen demonstrated a bulky mass measuring $10 \mathrm{~cm}$ in diameter in the left anterior mediastinum, multiple pulmonary nodules (measuring up to $3 \mathrm{~cm}$ in diameter), axillary lymph node swelling (Fig. 1), and a pancreatic tumor. She was therefore admitted to our hospital for further examination and symptom management. The patient's physical findings at the time of the first medical examination were as follows: pulse rate: $72 / \mathrm{min}$ (regular pulse), blood pressure: $128 / 80 \mathrm{mmHg}$, body temperature: $36.7^{\circ} \mathrm{C}$, and oxygen saturation $\left(\mathrm{SpO}_{2}\right)$ : $97 \%$ in room air. The patient exhibited no external abnormalities. Normal findings were ob-

\footnotetext{
${ }^{1}$ Department of Respiratory Medicine, Japanese Red Cross Nagasaki Genbaku Hospital, Japan, ${ }^{2}$ Clinical Oncology Center, Nagasaki University Hospital, Japan, ${ }^{3}$ Department of Hematology Medicine, Japanese Red Cross Nagasaki Genbaku Hospital, Japan, ${ }^{4}$ Department of Pathology, Japanese Red Cross Nagasaki Genbaku Hospital, Japan, ${ }^{5}$ Department of Respiratory Medicine, Tochigi Cancer Center, Japan and ${ }^{6}$ Second Department of Internal Medicine, Nagasaki University Hospital, Japan

Received for publication January 14, 2016; Accepted for publication March 4, 2016

Correspondence to Dr. Minoru Fukuda, mifukuda258@ nifty.com
} 

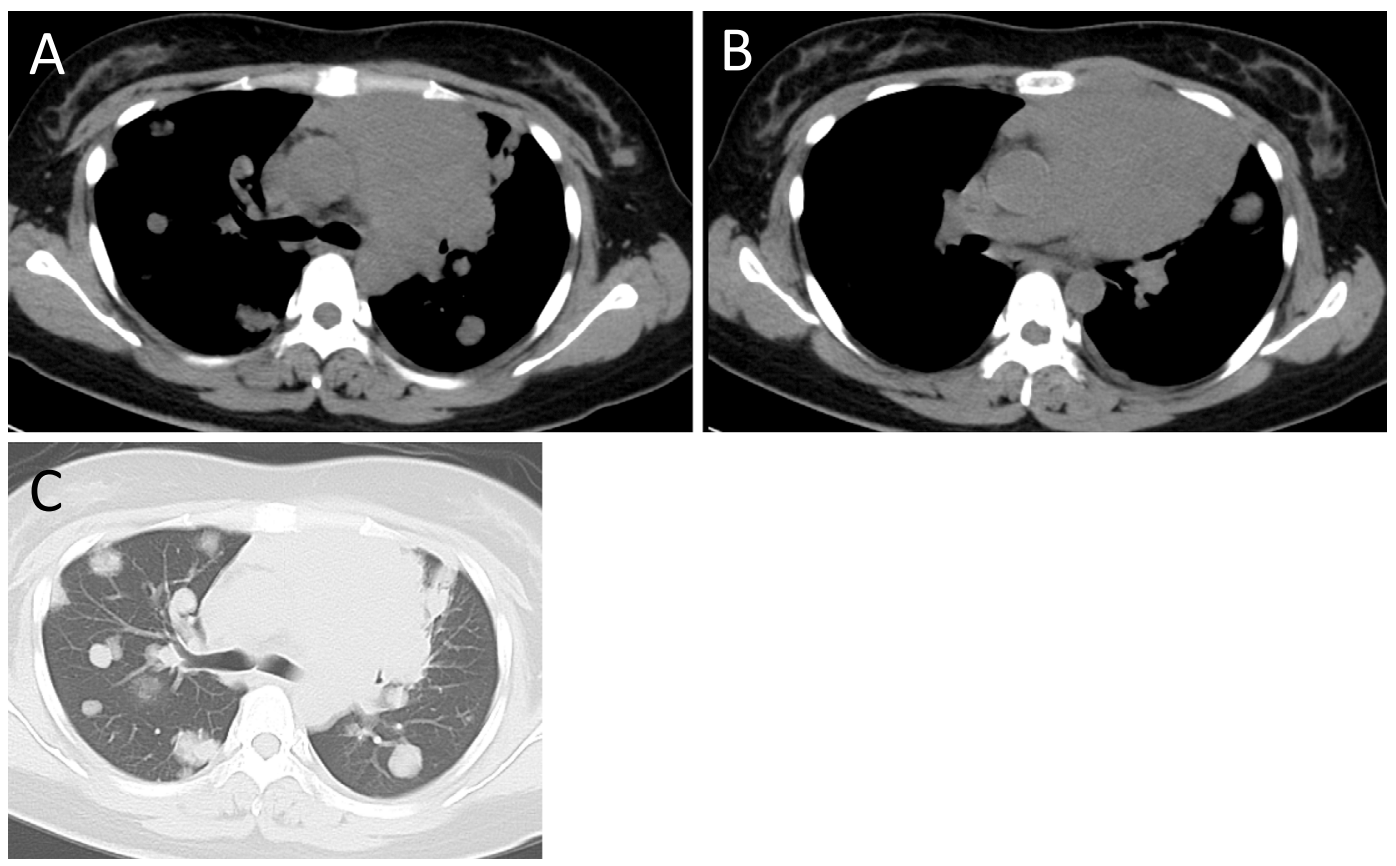

Figure 1. Computed tomographic images of the chest with the mediastinal $(A, B)$ and lung window settings $(C)$ obtained at onset.

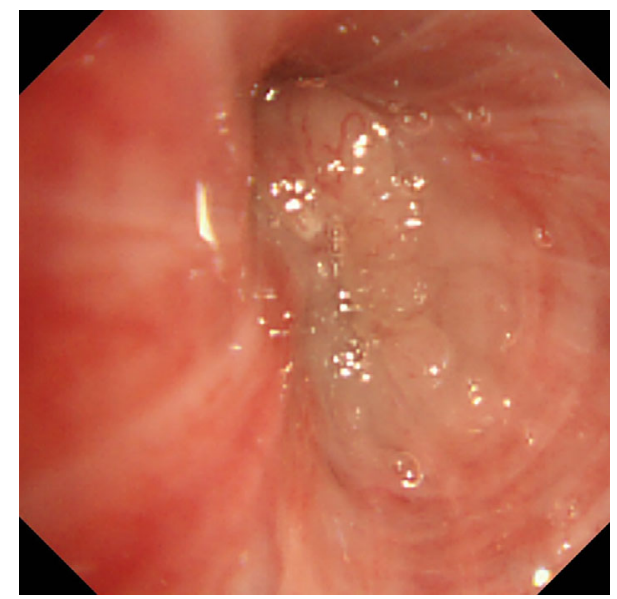

Figure 2. Fiberoptic bronchoscopy findings of the lingular segment of the left lung.

tained during auscultatory examinations of the patient's chest and heart. Serological tests revealed the following findings: C-reactive protein level: $5.24 \mathrm{mg} / \mathrm{dL}$, lactate dehydrogenase level: $979 \mathrm{IU} / \mathrm{L}$, fibrinogen level: $509 \mathrm{mg} / \mathrm{dL}$, ddimer level: $1.8 \mu \mathrm{g} / \mathrm{mL}$, and fibrin degradation product level: $9.19 \mu \mathrm{g} / \mathrm{mL}$. Tumor marker tests detected elevated soluble interleukin-2 receptor $(1,660 \mathrm{U} / \mathrm{mL})$ levels.

Fiberoptic bronchoscopy revealed a white-tinged irregularly shaped endobronchial tumor accompanied by capillary vessel dilatation in the left upper lobar bronchus, which was found to be almost completely obstructed (Fig. 2). A histological examination detected bright cell bodies of various sizes and tumor cells with naked nuclei. The cells exhibited a proliferative and invasive activity, but they had not yet formed a well-defined structure (Fig. 3), and an immunohis-

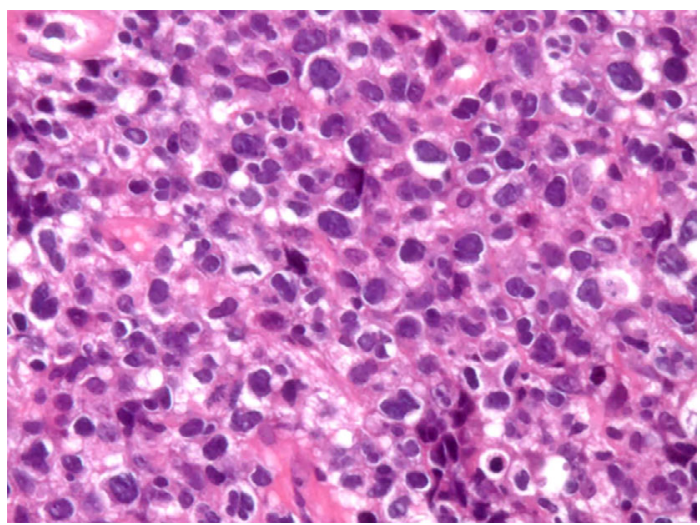

Figure 3. Pathological features observed during Hematoxylin and Eosin staining.

tochemical examination showed the tumor cells to be negative for CD3 (Fig. 4A), CD56, synaptophysin, and AE1/AE3 (data not shown), while they were positive for CD20 (Fig. 4B) and leukocyte common antigen. Histologically, the tumor was diagnosed to be diffuse large B-cell lymphoma, and as the primary tumor developed in the mediastinum we finally diagnosed the patient with PMLBCL. The patient was treated with R-CHASE (rituximab, cyclophosphamide, high-dose arabinoside, steroids, and etoposide) chemotherapy and achieved a tumor response (Fig. 5). Tumor marker tests also detected normalized soluble interleukin-2 receptor (314 U/mL) levels.

\section{Discussion}

PMLBCL was first described in the early 1980s $(6,7)$ and is one of the subtypes of DLBCL. It constitutes from 2- 

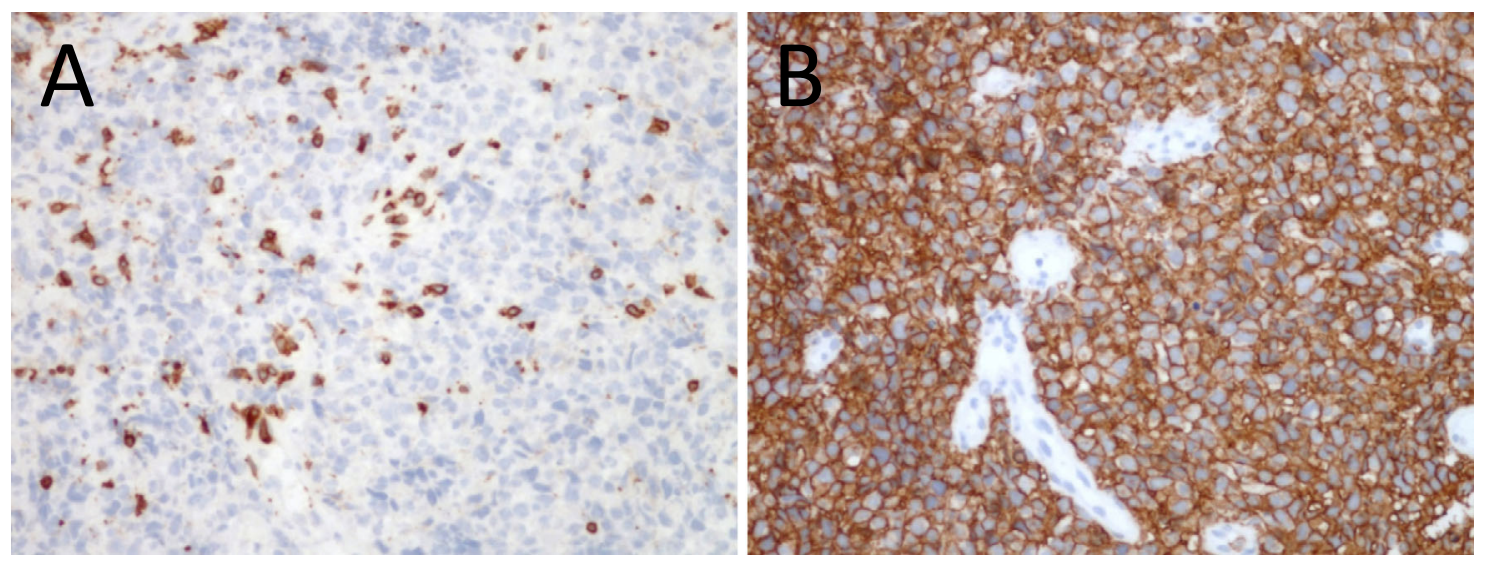

Figure 4. Pathological features observed during an immunohistochemical examination of the CD3 (A) and CD20 (B) expression.
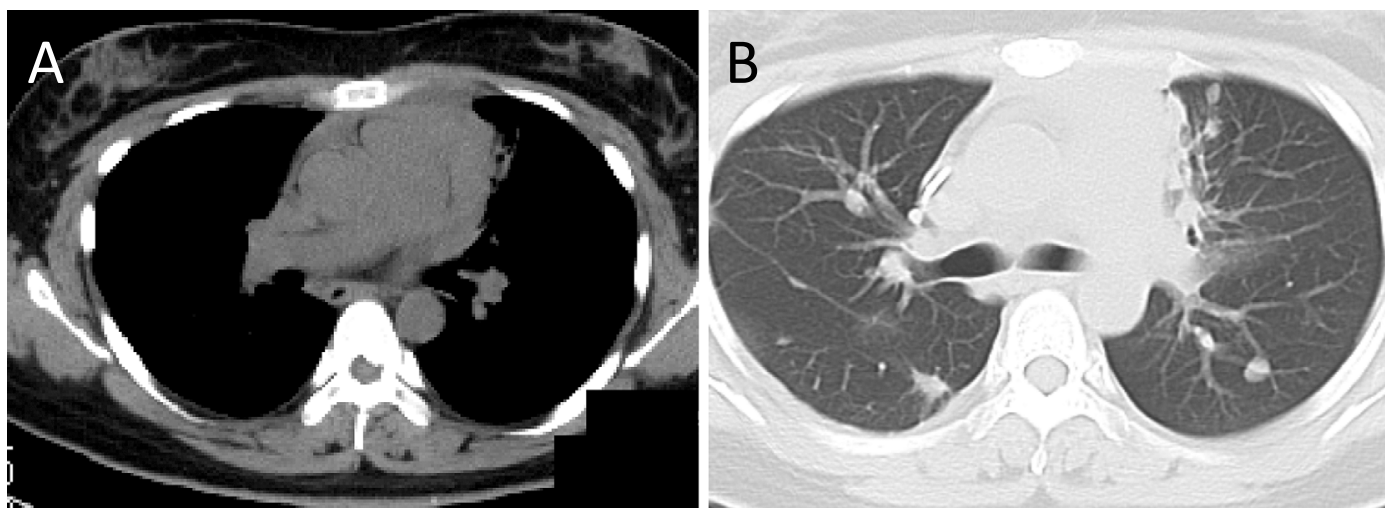

Figure 5. Computed tomographic images of the chest with the mediastinal (A) and lung window settings (B) obtained after one cycle of R-CHASE treatment.

$3 \%$ of all non-Hodgkin's lymphomas and from $6-10 \%$ of all DLBCL (1-4). No particular risk factors for this disease have been identified. It commonly presents as a bulky lesion in the anterior-superior mediastinum and is associated with symptoms related to local invasion or compression, including dyspnea, coughing, chest pain, and dysphagia $(8,9)$. It tends to occur in younger adults and exhibits a female predominance (median age: 30 to 40 years; male to female ratio: 1:2). In the present case, the patient was in her 30 s and presented with a bulky mediastinal mass and anterior and back pain, coughing, dyspnea, nausea, and fatigue.

Fluoroscopy- or computed tomography-guided needle biopsies often yield sufficient amounts of tissue specimens for a diagnostic workup and to prepare paraffin-fixed tissue sections for histological examinations and immunohistochemical analyses (4). Recently, EBUS-TBNA was reported to be useful for diagnosing primary mediastinal malignant lymphoma $(9,10)$. In the present case, fiberoptic bronchoscopy detected endobronchial involvement, and we were able to obtain tumor samples from the lingular segment of the left lung and thus diagnose PMLBCL without EBUS-TBNA. The development of extrapulmonary malignant tumors in the endobronchial region is uncommon and is mainly associated with colon, breast, and kidney cancer $(11,12)$. Although lymphomas often occur in the lungs, endobronchial lymphoma is extremely rare, and very few of the cases reported in the literature were diagnosed by bronchoscopy. For example, no endobronchial lesions were detected in a study of 55 patients who were diagnosed with non-Hodgkin's lymphoma (13), and only one endobronchial lesion was seen among 93 patients with primary lung lymphoma (14). Endobronchial lymphoma can be categorized into two types. The first involves the accumulation of diffuse submucosal infiltrates due to the lymphangitic or hematogenous spread of systemic lymphoma such as colon, breast and lung cancer. The other type, to which the present case belongs, involves the development of a localized nodule in the airway due to the direct spread of lymphoma from the neighboring lymph nodes or the de novo development of such a lesion from bronchus-associated lymphoid tissue. Bronchoscopy or EBUS-TBNA should be performed to screen for endobronchial involvement in cases involving a mediastinal mass and multiple pulmonary nodules.

The optimum chemotherapy regimen for PMLBCL has not yet been established, and several approaches from firstgeneration cyclophosphamide (CHOP)-like regimens to third-generation multi-drug chemotherapy regimens have been tried (15). In the present case, the patient was treated 
with the R-CHASE regimen and achieved a partial response. R-CHASE is a combination chemotherapy regimen in which rituximab is added to the CHASE regimen (cyclophosphamide, cytosine arabinoside, etoposide, and dexamethasone) developed by the Aichi Cancer Center (16). In a pilot phase I/II study of patients with refractory or relapsed lymphoma, the CHASE regimen achieved a complete response rate of $71.4 \%$ in 14 patients. Recently, Dunleavy et al. administered the dose-adjusted etoposide, doxorubicin, and cyclophosphamide with vincristine, prednisone, and rituximab (DA-EPOCH-R) regimen in combination with filgrastim (without radiotherapy) and achieved an event-free survival rate of $93 \%$ and an overall survival rate of $97 \%$ during a median follow-up period of 5 years (17). The latter approach might thus become the new standard treatment for PMLBCL.

In conclusion, we herein reported a case of PMLBCL exhibiting endobronchial involvement, in which the disease was diagnosed by bronchoscopy and treated with RCHASE. Although endobronchial PMLBCL lesions are rare, we consider that bronchoscopy should be promptly performed when a mediastinal mass and pulmonary lesions are observed on CT.

The authors state that they have no Conflict of Interest (COI).

\section{References}

1. Cazals-Hatem D, Repage E, Brice P, et al. Primary mediastinal large B-cell lymphoma: a clinocopathologic study of 141 cases compared with 916 nonmediastinal large B-cell lymphoma, a GELA study. Am J Surg Pathol 20: 877-888, 1996.

2. Barth TF, Leithauser F, Joos S, Bentz M, Moller P. Mediastinal (thymic) large B-cell lymphoma: where do we stand? Lancet Oncol 3: 229-234, 2002.

3. Wang E, Stoecker M. Primary mediastinal (thymic) large B-cell lymphoma with aberrant expression of CD3: a case report with review of the literature. Int J Hematol 91: 509-515, 2010.

4. Hutchinson CB, Wang E. Primary mediastinal (thymic) large Bcell lymphoma: a short review with brief discussion of mediastinal gray zone lymphoma. Arch Pathol Lab Med 135: 394-398, 2011.
5. Kennedy MP, Jimenez CA, Bruzzi JF, et al. Endobronchial ultrasound-guided transbronchial needle aspiration in the diagnosis of lymphoma. Thorax 63: 360-365, 2008.

6. Levitt LJ, Aisenberg AC, Harris NL, Linggood RM, Poppema S. Primary non-Hodgkin's lymphoma of the mediastinum. Cancer 50: 2486-2492, 1982.

7. Trump DL, Mann RB. Diffuse large cell and undifferentiated lymphomas with prominent mediastinal involvement. Cancer 50: 277282, 1982.

8. Lazzarino M, Orlandi E, Paulli M, et al. Treatment outcome and prognostic factors for primary mediastinal (thymic) B-cell lymphoma: a multicenter study of 106 patients. J Clin Oncol 15: 1646-1653, 1997.

9. Steinfort DP, Conron M, Tsui A, et al. Endobronchial ultrasoundguided transbronchial needle aspiration for the evaluation of suspected lymphoma. J Thorac Onchol 5: 804-809, 2010.

10. Inoue $\mathrm{M}$, Nakajima $\mathrm{T}$, Tsujimura $\mathrm{H}$, et al. Mediastinal follicular lymphoma diagnosed with multidirectional analysis using tissue samples obtained by EBUS-TBNA. Intern Med 49: 2147-2149, 2010.

11. Katsimbri PP, Bamias AT, Froudarakis ME, Peponis IA, Constantopoulos SH, Pavlidis NA. Endobronchial metastases secondary to solid tumors: report of eight cases and review of the literature. Lung Cancer 28: 163-170, 2000.

12. Kiryu T, Hoshi H, Matsui E, et al. Endotracheal/endobronchial metastases: clinicopathologic study with special reference to developmental modes. Chest 119: 768-775, 2001.

13. Vieta JO, Craver LF. Intrathoracic manifestations of the lymphomatoid diseases. Radiology 37: 133-159, 1941.

14. Pappaioannau NA, Watson WI. Primary lymphoma of the lung; an appraisal of its natural history and a comparison with other localized lymphoma. J Thorac Cardiovasc Surg 49: 373-387, 1965.

15. Martelli M, Ferreri AJ, Johnson P. Primary mediastinal large Bcell lymphoma. Crit Rev Oncol Hematol 68: 256-263, 2008.

16. Ogura M, Kagami Y, Taji H, et al. Pilot phase I/II study of new salvage therapy (CHASE) for refractory or relapsed malignant lymphoma. Int J Hematol 77: 503-511, 2003.

17. Dunleavy K, Pittaluga S, Maeda LS, et al. Dose-adjusted EPOCHRituximab therapy in primary mediastinal B-cell lymphoma. N Engl J Med 368: 1408-1416, 2013.

The Internal Medicine is an Open Access article distributed under the Creative Commons Attribution-NonCommercial-NoDerivatives 4.0 International License. To view the details of this license, please visit (https://creativecommons.org/licenses/ by-nc-nd/4.0/).

(C) 2016 The Japanese Society of Internal Medicine http://www.naika.or.jp/imonline/index.html 